\title{
Toll-like receptor 5 (TLR5) expression is a novel predictive marker for recurrence and survival in squamous cell carcinoma of the tongue
}

\author{
J H Kauppila*,1,2,3, A E Mattila ${ }^{1,3}$, T J Karttunen ${ }^{1,3}$ and T Salo ${ }^{3,4,5}$ \\ ${ }^{1}$ Department of Pathology, University of Oulu, PO Box 5000, 90014 Oulu, Finland; ${ }^{2}$ Department of Surgery, University of Oulu, \\ PO Box 5000, 90014 Oulu, Finland; ${ }^{3}$ Oulu University Hospital, PO Box 21, 90029 Oulu, Finland; ${ }^{4}$ Institute of Dentistry, University of \\ Oulu, PO Box 5000, 90014 Oulu, Finland and ${ }^{5}$ Institute of Dentistry, University of Helsinki, 00014 Helsinki, Finland
}

Background: Toll-like receptor 5 (TLR5) is an immune receptor recognising bacterial flagellin. Activation of TLR5 results in cancer invasion and cytokine release. As certain bacteria have been linked to oral cancer, we wanted to study TLR5 expression in oral tongue squamous cell carcinoma (OTSCC).

Methods: Samples from 119 patients with OTSCC were obtained, including 101 samples of adjacent normal lingual mucosa. The TLR5 histoscore (0-300) was assessed semiquantitatively by immunohistochemistry in a blinded manner.

Results: Toll-like receptor 5 was expressed in 84 normal epithelia and 118 cancer samples. Expression of TLR5 was increased in cancer when compared with normal lingual epithelium (median histoscore 15 vs 135). In cancer, higher TLR5 was associated with age of $>70$ years at the time of diagnosis, female gender and disease recurrence. No association between TLR5 expression and tumour grade, stage or treatment was found. In multivariate analysis, TLR5 was an independent predictor of cancer mortality (hazard ratio (HR) 3.587, 95\% confidence interval (Cl) (1.632-7.882)) and disease recurrence ( $\mathrm{HR} 4.455,95 \% \mathrm{Cl}(2.168-9.158))$.

Conclusion: Toll-like receptor 5 has a previously undescribed role in the pathophysiology of OTSCC and might represent a link between bacteria and cancer. It could be a useful marker for predicting recurrence or survival of OTSCC patients.

Toll-like receptors (TLRs) are evolutionarily conserved receptors of the innate immune system (Takeda et al, 2003). The 13 TLRs recognise their unique pathogen-associated molecular patterns like bacterial lipopolysaccharide (TLR4), DNA (TLR9) or flagellin (TLR5) (Takeda et al, 2003; Akira and Takeda, 2004). Activation of TLR induces various molecules activating the immune response (Takeda et al, 2003; Akira and Takeda, 2004; Li et al, 2009).

Increased expression of TLRs has been found to associate with the different types of cancer (Schmausser et al, 2005; Rydberg et al, 2009; Pimentel-Nunes et al, 2011; Song et al, 2011; Park et al, 2011a), including the development of gastric cancers (Schmausser et al, 2005; Pimentel-Nunes et al, 2011). Toll-like receptor 5 has been shown to regulate gastric cancer cell proliferation (Song et al, 2011). Interestingly, increased amount of TLR5 has been described in dysplasia of the stomach as well as in uterine cervix, suggesting that TLR5 may have a role in carcinogenesis (Kim et al, 2008). Thus, TLR5 might help identify dysplastic lesions in epithelium (Kim et al, 2008; Pimentel-Nunes et al, 2011).

Former studies show that TLR5 is expressed in normal and neoplastic human salivary gland cells (Park et al, 2011a). Activation of TLR5 by flagellin has been shown to induce migration and invasion in adenocarcinoma cells of the human salivary gland (Park et al, 2011a). Also, head and neck squamous cell carcinomas have been shown to express TLR5 (Rydberg et al, 2009; Park et al, 2010). 
Oral tongue squamous cell carcinomas (OTSCCs) comprise one third of intraoral cancers and their risk factors include, for example, tobacco, alcohol and poor oral hygiene (Moller, 1989; Rosenquist et al, 2005; Gillison, 2007). Even with the recent advances in their treatment, the 5-year survival remains around 50\% (Sano and Myers, 2007). Various molecular markers and factors have been proposed for risk assessment of OTSCC survival or recurrence, but none are currently in clinical use (Bello et al, 2011; Bonnardot et al, 2011; Kim et al, 2011).

Expression of TLR5 in oral squamous cell carcinomas has not been studied before. The aim of this study was to assess whether the TLR5 expression would relate to clinicopathological variables and if it could predict survival or recurrence of tongue squamous cell carcinoma patients.

\section{MATERIALS AND METHODS}

Patients. Paraffin-embedded, archival resection specimens of OTSCC $(n=119)$ were obtained from the Department of Pathology, Oulu University Hospital, between the years 19812009. The median age of the patients was 66 years (range 27-99). The median follow-up time was 121 months (range 24-298 months) in the surviving patients. The median survival for the study patients was 51 months (range 1-298 months). The patient survival data were acquired from Statistics Finland and other relevant data from the patient records (Table 1). We were unable to retrieve treatment data from three of the patients and follow-up data from two of the patients. The use of the patient samples and the data enquiry were approved by the Oulu University Hospital Ethics Committee and by the National Authority for Medicolegal Affairs (VALVIRA).

Immunohistochemistry. Immunohistochemistry was performed on the tissue block sections, which were first selected on the basis of haematoxylin and eosin stainings, to be representative for the tumour mass in the resected specimen. The TLR5 immunostainings were performed with a commercial monoclonal mouse antibody (IMG-664A, IgG2a, Clone 19D759.2, Imgenex, San Diego, CA, USA), with dilution of 1:150. For immunohistochemical detection of the antibody reaction, we used Dako Envision kit (Dako, Copenhagen, Denmark) with a high temperature antigen retrieval in Tris-EDTA buffer for $15 \mathrm{~min}$. Diaminiobenzidine (Dako basic DAB-kit) was used as a chromogen. All the stainings were done with Dako Autostainer (Dako). Validation of our immunohistochemical analysis was performed through two series of negative controls (by omitting the primary antibody and by replacing primary antibody with mouse primary antibody isotype control).

Assessment of TLR5 expression. Immunoreaction of TLR5 was analysed by two independent researchers (JHK and AM) blinded from the clinical data. The staining intensities and the percentage of positive cells were separately assessed in the primary tumour tissue $(n=119)$ and adjacent normal squamous epithelium $(n=101)$. As the TLR5 staining was not uniform in different parts of the epithelium or cancerous tissue (Figures 1 and 3), we chose to use a modified histoscore method, as described earlier (Kauppila et al, 2011), to combine the TLR5 intensity and percentage of TLR5 expressing cells. More specifically, the staining intensity was assessed with a four-point scale from negative $(0)$ to weak (1), moderate (2) and strong intensity (3). The extent of the staining was expressed as percentage of positive cells $(0-100 \%)$ by $10 \%$ intervals. The mean values of the two independent estimates were used if the estimated staining intensity scores did not differ more than by one step, or if the difference of proportion of positive cells was $<30 \%$. In cases with more extensive differences between the assessors a consensus was reached after a re-evaluation. The
Table 1. Baseline characteristics of the patients

\begin{tabular}{|l|c|c|}
\hline Patient clinical data & $\mathbf{N}$ & $\%$ \\
\hline Total & 119 & 100.0 \\
\hline
\end{tabular}

Age at diagnosis

\begin{tabular}{|l|l|l|}
\hline$<55$ years & 37 & 31.1 \\
$55-70$ years & 33 & 27.7 \\
$>70$ years & 49 & 41.2 \\
\hline
\end{tabular}

Sex

\begin{tabular}{|l|l|l|}
\hline Male & 58 & 48.7 \\
Female & 61 & 51.3 \\
\hline
\end{tabular}

Tumour grade

\begin{tabular}{|l|l|}
\hline 1 & 41 \\
2 & 63 \\
3 &
\end{tabular}

Tumour stage

\begin{tabular}{|l|l|l|}
\hline $1-2$ & 61 & 51.3 \\
$3-4$ & 58 & 48.7 \\
\hline
\end{tabular}

Neck lymph nodes

\begin{tabular}{|l|l|l|}
\hline Negative & 78 & 65.5 \\
Positive & 41 & 34.5 \\
\hline
\end{tabular}

\section{Recurrence}

\begin{tabular}{|l|r|r|}
\hline No & 78 & 65.5 \\
Yes & 41 & 34.5 \\
\hline Adjuvant therapy & 68 & 57.1 \\
\hline No & 38 & 31.9 \\
Radiotherapy & 10 & 8.4 \\
Radio- and chemotherapy & 3 & 2.5 \\
Missing
\end{tabular}

TLR5 histoscore was counted by multiplying the mean of intensity level by the mean percentage of positive cells, resulting in a value between 0 and 300. Data were divided into groups by histoscore levels. Accordingly, the cancer specimens were dichotomised by TLR 5 expression score based on the median to the groups of 'weak expression' (scores 0-135) and 'strong expression' (scores 136-300).

Statistical analysis. For statistical analyses, we used SPSS 17.0 (SPSS Inc., Chicago, IL, USA) and Prism 6 for Mac OS X (GraphPad Software Inc., La Jolla, CA, USA). Chi-square test was used to calculate statistically significant differences between prognostic and clinicopathologic variables. To compare the TLR5 expression in normal and cancerous tissue, independent samples $t$ test and paired samples $t$-test were used. The correlation of staining intensity and percentage was done with Spearman's rho test. Life tables were calculated according to the Kaplan-Meier method, and the survival curves were compared with the log-rank test. Uni- and multivariate survival analysis was done with the Cox proportional hazards model using the following covariates: TLR5 expression (weak and strong), gender, age at the time of diagnosis $(<55$, 55-70 and $>70$ years), tumour stages (1-2 and 3-4), tumour histologic grades (1,2 and 3) and adjuvant therapy (no adjuvant therapy, radiotherapy or chemo- and radiotherapy). Multivariate analysis was done using backward stepwise selection of variables, and a $P$-value of 0.05 was adopted as the limit for inclusion of a covariate. The backward stepwise algorithm was used to pick the best combination of prognostic factors to explain the mortality or 

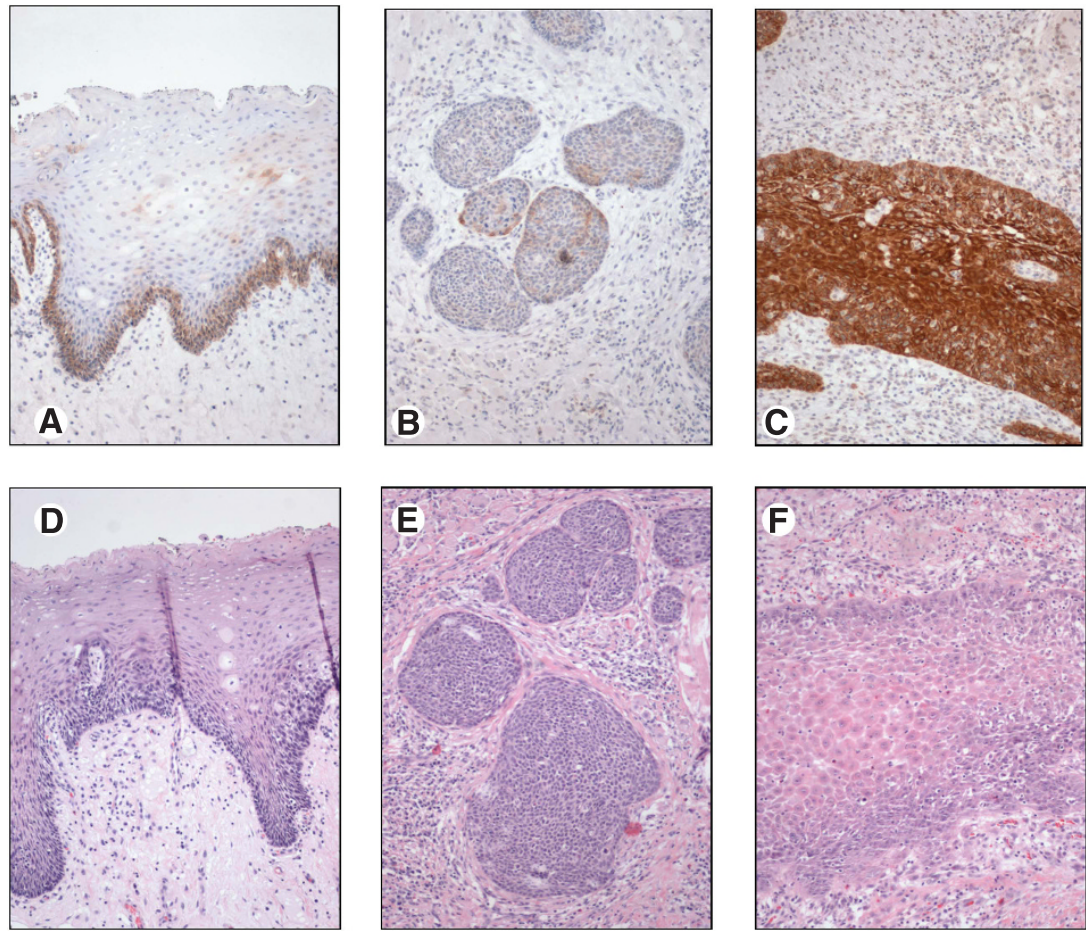

Figure 1. TLR5 expression in the normal epithelium and squamous cell carcinoma of the tongue. TLR5 is expressed in normal tongue epithelium (A). Examples of weak (B) and strong (C) expression of TLR5 in specimens of squamous cell carcinoma of the tongue. H\&E stainings of the corresponding sections (D-F, $\times 250)$.

recurrences in the study population. The hazard ratios (HRs) and 95\% confidence intervals (CIs) are provided for each covariate.

\section{RESULTS}

TLR5 is expressed in normal tongue epithelium. Toll-like receptor 5 was expressed in 84 (83.2\%) of the 101 normal adjacent squamous epithelia surrounding the tongue cancer tissue. The staining was localised in the cytoplasm and when present, mainly found in the basal layer of the epithelium (Figures $1 \mathrm{~A}$ and $3 \mathrm{~A}-\mathrm{C}$ ). Thus, the staining intensity varied from 0 to 3 and the percentage was mainly between 0 and 30 with a few higher percentages.

TLR5 expression is increased in OTSCC and associates with disease recurrence. Toll-like receptor 5 was expressed in 118 (99.2\%) of the 119 tumours evaluated, with predominantly cytoplasmic location of the immunoreaction (Figure $1 \mathrm{~B}$ and $\mathrm{C}$ ). The expression of TLR5 in cancerous tissue was increased in both stage 1-2 and stage 3-4 cancers, when compared with adjacent normal epithelium $(P<0.001$, Figures 2 and 3$)$. Median histoscores in normal mucosa, stage 1-2 cancer and stage 3-4 cancer were 15, 135 and 130, accordingly. The median histoscore for all cancers was 135 . The variance of staining percentage was higher in cancer tissue than in normal mucosa the percentage ranging from 0 to 100 , with only one negative sample. The intensities ranged between 0 and 3 and there was a correlation between the staining intensity and percentage $(\rho=0.742, P<0.001)$.

We found significant association between weak TLR5 expression and younger age $(P<0.01)$, male gender $(P<0.05)$, as well as strong TLR5 expression and disease recurrence $(P<0.001)$. No significant association was detected between TLR5 expression and tumour grade, stage, lymph-node status or treatment. The associations are summarised in Table 2.

Survival and recurrence, univariate analysis. We analysed the effect of TLR5 on disease recurrence as well as cancer mortality.

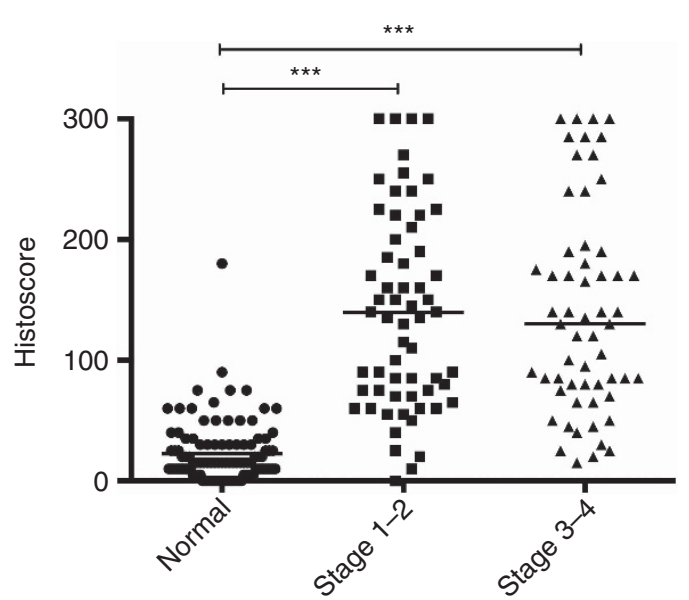

Figure 2. A dot plot of TLR5 expression in normal oral mucosa, stage 1-2 cancers and stage 3-4 cancers. Lines show median histoscore in each group. ${ }^{\star \star \star} P<0.001$.

Strong TLR5 expression was associated with reduced disease-free survival $(P<0.001$, Figure $4 \mathrm{~B})$. Strong TLR5 expression was also associated with increase in cancer-specific mortality $(P<0.01$, Figure 4A).

Strong TLR5 expression is an independent predictor of survival in multivariate analysis. Multivariate analysis (Table 3), $n=117$, 39 events, identified strong TLR5 expression as an independent prognostic factor (HR 3.587, 95\% CI (1.632-7.882)) for cancerspecific deaths, along with poor grade of differentiation and high disease stage (III-IV). Strong TLR5 expression was also identified as an independent predictor of recurrences (HR 4.455, 95\% CI $(2.168-9.158))$. 

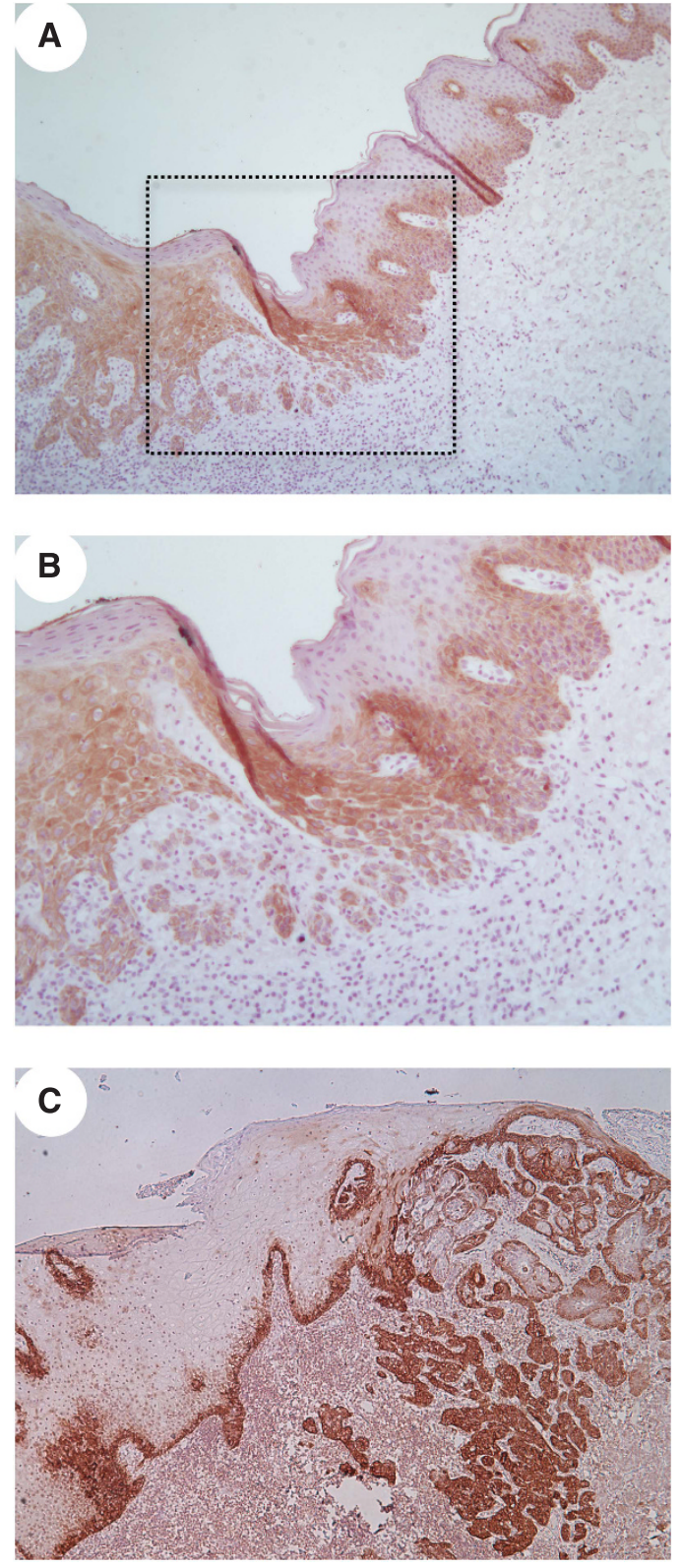

Figure 3. TLR5 expression in two samples including transitional zones between normal oral mucosa and squamous cell carcinoma. Examples of stage 1-2 cancer (A), magnified in (B) and stage 3-4 cancer (C).

\section{DISCUSSION}

Toll-like receptor 5 recognises bacterial flagellin and it has been shown to affect cancer progression in vitro (Akira and Takeda, 2004; Park et al, 2011a). In this study, we show for the first time that TLR5 expression is increased in OTSCC when compared with surrounding normal lingual epithelium. We also demonstrate that TLR5 expression is an independent predictor of OTSCC mortality and disease recurrence.

Inflammation caused by microbial infections is known as a carcinogenetic factor for many cancers, for example, Helicobacter pylori infection and gastric cancer (Meurman, 2010). Human papilloma virus (HPV) infection is a defined risk factor for oral squamous cell carcinoma, but its prevalence in cancers of the mobile tongue is much lower than in cancers of the base of the tongue (Dahlgren et al, 2004; Gillison, 2007; Harris et al, 2011).
Table 2. Tumour TLR5 status and clinical correlations

\begin{tabular}{|c|c|c|c|}
\hline & \multicolumn{3}{|c|}{ TLR5 expression } \\
\hline & Weak, n (\%) & Strong, $\mathbf{n}(\%)$ & $P$-value \\
\hline \multicolumn{4}{|l|}{ Age at diagnosis } \\
\hline$<55$ years & $27(73.0)$ & $10(27.0)$ & \\
\hline $55-70$ years & $12(36.4)$ & $21(63.6)$ & \\
\hline$>70$ years & $23(46.9)$ & $26(53.1)$ & $<0.01$ \\
\hline \multicolumn{4}{|l|}{ Sex } \\
\hline Male & $36(62.1)$ & 22 (37.9) & \\
\hline Female & $26(42.6)$ & $35(57.4)$ & $<0.05$ \\
\hline \multicolumn{4}{|l|}{ Tumour grade } \\
\hline 1 & $18(43.9)$ & $23(56.1)$ & \\
\hline 2 & $35(55.6)$ & 28 (44.4) & \\
\hline 3 & $9(60.0)$ & $6(40.0)$ & NS \\
\hline \multicolumn{4}{|l|}{ Tumour stage } \\
\hline $1-2$ & $31(50.8)$ & $30(49.2)$ & \\
\hline $3-4$ & $31(53.4)$ & $27(46.6)$ & NS \\
\hline \multicolumn{4}{|l|}{ Neck lymph nodes } \\
\hline Negative & $43(55.1)$ & $35(44.9)$ & \\
\hline Positive & $19(46.3)$ & $22(53.7)$ & NS \\
\hline \multicolumn{4}{|l|}{ Recurrence } \\
\hline No & $52(66.7)$ & $26(33.3)$ & \\
\hline Yes & $10(24.4)$ & $31(75.6)$ & $<0.001$ \\
\hline \multicolumn{4}{|l|}{ Adjuvant treatment } \\
\hline No & $36(52.9)$ & $32(47.1)$ & \\
\hline RT & 18 (47.4) & $20(52.6)$ & \\
\hline RT and chemotherapy & $5(50.0)$ & $5(50.0)$ & NS \\
\hline
\end{tabular}

Presence of HPV in oropharyngeal cancers seem to associate with better prognosis (Park et al, 2011b). Thus, other factors explaining the mortality related to OTSCC are needed.

In the oral cavity, the role of microbiota in carcinogenesis is currently unknown, even though poor oral hygiene is a risk factor for OTSCC (Rosenquist et al, 2005). Interestingly, it has been shown that Streptococcus mitis, Prevotella melaninogenica and Capnocytophaga gingivalis species are prevalent in oral cancer patients with high specificity and sensitivity (Mager et al, 2005). Their effect on oral carcinogenesis, however, remains to be revealed. Acetaldehyde production by bacteria might partly explain the link between bacteria and oral cancer as well as the effect of alcohol consumption on oral cancer (Meurman, 2010).

Earlier reports by us and others have demonstrated a role for various TLRs in cancer progression, as well as immune responses against cancer (Merrell et al, 2006; Ren et al, 2007; JukkolaVuorinen et al, 2008; Yang et al, 2009; Oblak and Jerala, 2011; Takala et al, 2011). Polymorphisms of TLR have also been found to affect cancer development (Kutikhin, 2011; Zeng et al, 2011). Expression of TLR5 has been shown to increase during gastric and colorectal carcinogenesis, as well as in precancerous lesions of uterine cervix (Kim et al, 2008; Pimentel-Nunes et al, 2012a, b). Toll-like receptor 5 has also been proposed as a biomarker for gastric and cervical dysplasias, because its expression increases through stages of cancer development (Kim et al, 2008; PimentelNunes et al, 2011). In various gastric cancer cell lines, stimulation 

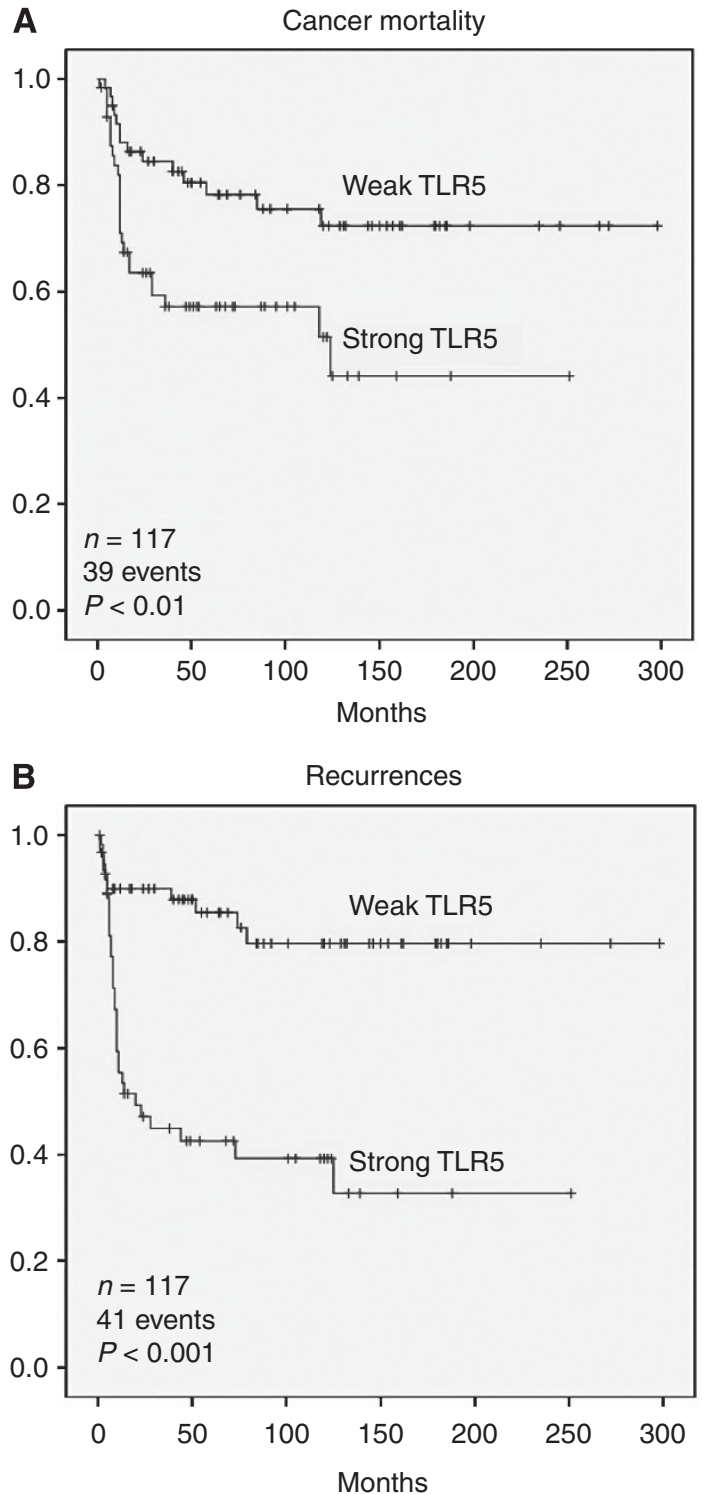

Figure 4. Kaplan-Meier survival curve demonstrating cumulative cancer mortality (A) and cancer recurrences (B) stratified by TLR5 expression.

with flagellin increased proliferation and induced IL-8 via TLR5 (Song et al, 2011). In breast cancer, for example, TLR5 expression was increased in ductal adenocarcinoma cells (Cai et al, 2011). In contrary to gastric cancer, activation by flagellin resulted in tumour suppressive effects in some of the breast cancer cell lines, whereas other cell lines were unresponsive to flagellin (Cai et al, 2011). Antitumor effect by flagellin has also been demonstrated in a pharyngeal carcinoma cell line (Rydberg et al, 2009). In salivary gland cancer cells, TLR5 activation induced invasion and proliferation (Park et al, 2011a). According to the studies by Park et al (2010) TLR5 activation, despite the increase in production of tumour-promoting IL-6 and IL-8, did not influence cell proliferation, invasion, migration or angiogenesis in moderately differentiated YD-10B OTSCC cells (). However, the effect of TLR5 stimulation on OTSCC progression may not be generalised from in vitro experiments with only single cell line.

The downstream effects and functionality of TLR5 seem to be dependent on cancer type, location and cell line. One explanation would be the mucosal bacteria, which are abundant in the gastrointestinal tract, but less prevalent for example in the mammary glands. During carcinogenetic changes, the expression pattern of TLR5 changes from basolateral to diffuse or increases on
Table 3. Multivariate analysis

\begin{tabular}{|l|c|c|}
\hline \multicolumn{2}{|l|}{ HR } & $95 \% \mathrm{Cl}$ \\
\hline \multicolumn{2}{|c|}{ Multivariate analysis: cancer mortality } & \\
\hline $\begin{array}{l}\text { Tumour stage } \\
1-2\end{array}$ & 1.000 & $1.999-9.200$ \\
$3-4$ & 4.288 & \\
\hline Tumour grade & & \\
1 & 1.000 & $0.427-1.919$ \\
2 & 0.905 & $1.257-8.255$ \\
3 & 3.221 & \\
\hline TLR5 expression & & $1.632-7.882$ \\
Weak & 1.000 & 3.587 \\
Strong &
\end{tabular}

Multivariate analysis: cancer recurrence

\begin{tabular}{|l|l|l|}
\hline TLR5 expression & 1.000 & \\
Weak & 4.455 & $2.168-9.158$ \\
Strong &
\end{tabular}

Abbreviations: $\mathrm{Cl}=$ confidence interval; $\mathrm{HR}=$ hazard ratio; $\mathrm{TLR} 5=$ Toll-like receptor 5 .

the luminal surface, as shown earlier, likely facilitating the recognition of bacterial particles (Kim et al, 2008; PimentelNunes et al, 2012a).

Our results suggest a link between TLR5 and oral squamous cell cancer progression. The bacterial flora changes during oral carcinogenesis and thus the flagella of oral bacteria could be recognised by TLR5, which in turn might affect the release of tumour promoting cytokines in cancer cells or induce cancer cell invasion (Park et al, 2010, 2011a). Thus, the composition of bacterial flora might also have a TLR5-dependent effect on cancer development. Oral tongue squamous cell carcinoma has low 5-year survival (Sano and Myers, 2007), but there are no clinically practical markers for risk assessment of OTSCC survival or recurrence (Bello et al, 2011; Bonnardot et al, 2011; Kim et al, 2011). Our study provides evidence for a relationship of TLR5 expression levels and prognosis in OTSCC. Multivariate analysis confirmed an independent association between high expression and recurrence of the tumour and poor survival. Similar prognostic value for TLR5 expression in cancer has not been demonstrated earlier.

There are some shortcomings in our study. The retrospective design may result in unknown biases in data. The long follow-up gives more reliable results, but the treatments have undergone slight changes during the 30 years, which cannot be controlled. Other things include the use of semiquantitative immunohistological assessment and the lack of functional TLR5 experiments.

In summary, we demonstrate a role for bacterial flagellin recognising TLR5 in OTSCC. Toll-like receptor 5 could be considered as a useful marker for predicting recurrence or survival of tongue carcinoma patients. It might be a useful tool to help recognise the OTSCC patients needing more intensive treatment and follow-up or even a potential new therapeutic target. The results should be evaluated using more extensive, prospective patient materials and in vitro functional studies to ensure these findings.

\section{ACKNOWLEDGEMENTS}

This research project was supported in part by grants from Cancer Foundation of Northern Ostrobotnia (JHK), Emil Aaltonen 
Foundation (JHK), Mary and Georg C Ehrnroot Foundation (JHK), Finnish Medical Foundation (JHK), Orion-Farmos Research Foundation (JHK), the Academy of Finland (TS), Sigrid Juselius Foundation (TS) and Finnish Dental Society Apollonia (TS). We thank Erja Tomperi for excellent technical assistance.

\section{CONFLICT OF INTEREST}

The authors declare no conflict of interest.

\section{REFERENCES}

Akira S, Takeda K (2004) Toll-like receptor signalling. Nat Rev Immunol 4: 499-511.

Bello IO, Vered M, Dayan D, Dobriyan A, Yahalom R, Alanen K, Nieminen P, Kantola S, Laara E, Salo T (2011) Cancer-associated fibroblasts, a parameter of the tumor microenvironment, overcomes carcinomaassociated parameters in the prognosis of patients with mobile tongue cancer. Oral Oncol 47: 33-38.

Bonnardot L, Bardet E, Steichen O, Cassagnau E, Piot B, Salam AP, Campion L, Ferron C, Beauvillain de Montreuil C, Malard O (2011) Prognostic factors for T1-T2 squamous cell carcinomas of the mobile tongue: a retrospective cohort study. Head Neck 33: 928-934.

Cai Z, Sanchez A, Shi Z, Zhang T, Liu M, Zhang D (2011) Activation of Tolllike receptor 5 on breast cancer cells by flagellin suppresses cell proliferation and tumor growth. Cancer Res 71: 2466-2475.

Dahlgren L, Dahlstrand HM, Lindquist D, Hogmo A, Bjornestal L, Lindholm J, Lundberg B, Dalianis T, Munck-Wikland E (2004) Human papillomavirus is more common in base of tongue than in mobile tongue cancer and is a favorable prognostic factor in base of tongue cancer patients. Int J Cancer 112: 1015-1019.

Gillison ML (2007) Current topics in the epidemiology of oral cavity and oropharyngeal cancers. Head Neck 29: 779-792.

Harris SL, Thorne LB, Seaman WT, Hayes DN, Couch ME, Kimple RJ (2011) Association of p16(INK4a) overexpression with improved outcomes in young patients with squamous cell cancers of the oral tongue. Head Neck 33: $1622-1627$.

Jukkola-Vuorinen A, Rahko E, Vuopala KS, Desmond R, Lehenkari PP, Harris KW, Selander KS (2008) Toll-like receptor-9 expression is inversely correlated with estrogen receptor status in breast cancer. J Innate Immun 1: 59-68.

Kauppila JH, Takala H, Selander KS, Lehenkari PP, Saarnio J, Karttunen TJ (2011) Increased Toll-like receptor 9 expression indicates adverse prognosis in oesophageal adenocarcinoma. Histopathology 59: 643-649.

Kim KY, Li S, Cha JD, Zhang X, Cha IH (2011) Significance of molecular markers in survival prediction of oral squamous cell carcinoma. Head Neck 34: 929-936.

Kim WY, Lee JW, Choi JJ, Choi CH, Kim TJ, Kim BG, Song SY, Bae DS (2008) Increased expression of Toll-like receptor 5 during progression of cervical neoplasia. Int J Gynecol Cancer 18: 300-305.

Kutikhin AG (2011) Association of polymorphisms in TLR genes and in genes of the Toll-like receptor signaling pathway with cancer risk. Hum Immunol 72: 1095-1116.

Li M, Zhou Y, Feng G, Su SB (2009) The critical role of Toll-like receptor signaling pathways in the induction and progression of autoimmune diseases. Curr Mol Med 9: 365-374.

Mager DL, Haffajee AD, Devlin PM, Norris CM, Posner MR, Goodson JM (2005) The salivary microbiota as a diagnostic indicator of oral cancer: a descriptive, non-randomized study of cancer-free and oral squamous cell carcinoma subjects. J Transl Med 3: 27.

Merrell MA, Ilvesaro JM, Lehtonen N, Sorsa T, Gehrs B, Rosenthal E, Chen D, Shackley B, Harris KW, Selander KS (2006) Toll-like receptor 9 agonists promote cellular invasion by increasing matrix metalloproteinase activity. Mol Cancer Res 4: 437-447.

Meurman JH (2010) Oral microbiota and cancer. J Oral Microbiol 2; doi:10.3402/jom.v2i0.5195.

Moller H (1989) Changing incidence of cancer of the tongue, oral cavity, and pharynx in Denmark. J Oral Pathol Med 18: 224-229.
Oblak A, Jerala R (2011) Toll-like receptor 4 activation in cancer progression and therapy. Clin Dev Immunol 2011: 609579.

Park JH, Yoon HE, Jeon DI, Ahn SG, Yoon JH (2010) Activation of TLR2 and TLR5 did not affect tumor progression of an oral squamous cell carcinoma, YD-10B cells. J Oral Pathol Med 39: 781-785.

Park JH, Yoon HE, Kim DJ, Kim SA, Ahn SG, Yoon JH (2011a) Toll-like receptor 5 activation promotes migration and invasion of salivary gland adenocarcinoma. J Oral Pathol Med 40: 187-193.

Park WS, Ryu J, Cho KH, Choi MK, Moon SH, Yun T, Chun BS, Lee GK, Ahn HJ, Lee JH, Vermeer P, Jung YS (2011b) Human papillomavirus in oropharyngeal squamous cell carcinomas in Korea: use of G1 cycle markers as new prognosticators. Head Neck 34: 1408-1417.

Pimentel-Nunes P, Afonso L, Lopes P, Roncon-Albuquerque Jr. R, Goncalves N, Henrique R, Moreira-Dias L, Leite-Moreira AF, Dinis-Ribeiro M (2011) Increased expression of toll-like receptors (TLR) 2, 4 and 5 in gastric dysplasia. Pathol Oncol Res 17: 677-683.

Pimentel-Nunes P, Goncalves N, Boal-Carvalho I, Afonso L, Lopes P, Roncon-Albuquerque Jr R, Henrique R, Moreira-Dias L, Leite-Moreira AF, Dinis-Ribeiro M (2012a) Helicobacter pylori Induces increased expression of toll-like receptors and decreased toll-interacting protein in gastric mucosa that persists throughout gastric carcinogenesis. Helicobacter doi:10.1111/hel.12008.

Pimentel-Nunes P, Goncalves N, Boal-Carvalho I, Afonso L, Lopes P, RonconAlbuquerque Jr R, Soares JB, Cardoso E, Henrique R, Moreira-Dias L, Dinis-Ribeiro M, Leite-Moreira AF (2012b) Decreased Toll-interacting protein and peroxisome proliferator-activated receptor gamma are associated with increased expression of Toll-like receptors in colon carcinogenesis. J Clin Pathol 65: 302-308.

Ren T, Wen ZK, Liu ZM, Liang YJ, Guo ZL, Xu L (2007) Functional expression of TLR9 is associated to the metastatic potential of human lung cancer cell: functional active role of TLR9 on tumor metastasis. Cancer Biol Ther 6: 1704-1709.

Rosenquist K, Wennerberg J, Schildt EB, Bladstrom A, Goran Hansson B, Andersson G (2005) Oral status, oral infections and some lifestyle factors as risk factors for oral and oropharyngeal squamous cell carcinoma. A population-based case-control study in southern Sweden. Acta Otolaryngol 125: $1327-1336$

Rydberg C, Mansson A, Uddman R, Riesbeck K, Cardell LO (2009) Toll-like receptor agonists induce inflammation and cell death in a model of head and neck squamous cell carcinomas. Immunology 128: e600-e611.

Sano D, Myers JN (2007) Metastasis of squamous cell carcinoma of the oral tongue. Cancer Metastasis Rev 26: 645-662.

Schmausser B, Andrulis M, Endrich S, Muller-Hermelink HK, Eck M (2005) Toll-like receptors TLR4, TLR5 and TLR9 on gastric carcinoma cells: an implication for interaction with Helicobacter pylori. Int J Med Microbiol 295: 179-185.

Song EJ, Kang MJ, Kim YS, Kim SM, Lee SE, Kim CH, Kim DJ, Park JH (2011) Flagellin promotes the proliferation of gastric cancer cells via the Toll-like receptor 5. Int J Mol Med 28: 115-119.

Takala H, Kauppila JH, Soini Y, Selander KS, Vuopala KS, Lehenkari PP Saarnio J, Karttunen TJ (2011) Toll-like receptor 9 is a novel biomarker for esophageal squamous cell dysplasia and squamous cell carcinoma progression. J Innate Immun 3: 631-638.

Takeda K, Kaisho T, Akira S (2003) Toll-like receptors. Annu Rev Immunol 21: $335-376$.

Yang HZ, Cui B, Liu HZ, Mi S, Yan J, Yan HM, Hua F, Lin H, Cai WF, Xie WJ, Lv XX, Wang XX, Xin BM, Zhan QM, Hu ZW (2009) Blocking TLR2 activity attenuates pulmonary metastases of tumor. PLOS ONE 4: e6520.

Zeng HM, Pan KF, Zhang Y, Zhang L, Ma JL, Zhou T, Su HJ, Li WQ, Li JY, Gerhard M, Classen M, You WC (2011) Genetic variants of toll-like receptor 2 and 5, helicobacter pylori infection, and risk of gastric cancer and its precursors in a chinese population. Cancer Epidemiol Biomarkers Prev 20: 2594-2602.

This work is published under the standard license to publish agreement. After 12 months the work will become freely available and the license terms will switch to a Creative Commons AttributionNonCommercial-Share Alike 3.0 Unported License. 